\title{
Evaluation of Risk Factors for Bleeding After Ultrasound-Guided Liver Biopsy
}

\author{
Haoyu Jing* \\ Zhanxiong $\mathrm{Yi}^{*}$ \\ Enhui $\mathrm{He}$ \\ Ruifang Xu \\ Xianquan Shi \\ $\mathrm{Li} \mathrm{Li}$ \\ Liying Sun \\ Ying Liu \\ Liang Zhang \\ Linxue Qian (D)
}

Beijing Friendship Hospital, Capital Medical University, Beijing, I00050,

People's Republic of China

*These authors contributed equally to this work
Correspondence: Linxue Qian

Beijing Friendship Hospital, Capital Medical University, Beijing, 100050, People's Republic of China

Tel +86-10-1331 II 00999

$\mathrm{Fax}+86-10-63138576$

Email Qianlinxue2002@I63.com
Purpose: This study was performed to analyze the risk factors for hemorrhagic complications after ultrasound-guided liver biopsies.

Patients and Methods: In this retrospective study, we reviewed 1193 ultrasound-guided percutaneous liver biopsies performed in our hospital from January 2018 to December 2020. Relevant patient characteristics, indications for biopsy, laboratory findings, biopsy technique, hemorrhagic complications, and pathologic outcomes were collected.

Results: We analyzed 834 procedures performed on 807 patients with complete data. The bleeding group comprised 45 patients with post-procedure bleeding, and non-bleeding group comprising the remaining 789 patients. Univariate analysis showed that age $(p<0.001)$, number of needle passes $(p=0.009)$, platelet count $(p=0.002)$, prothrombin time $(p<$ $0.001)$, and international normalized ratio $(p<0.001)$ were associated with post-procedure bleeding. Multivariable regression analysis showed that age under 18 years $(p<0.001)$, low platelet count $(p=0.001)$, and increased needle passes $(p=0.025)$ were independent risk factors for bleeding complications.

Conclusion: Sex and focal liver lesions did not affect the risk of post-procedure bleeding. The international normalized ratio and prothrombin time were associated with an increased incidence of bleeding; however, they had no predictive value. Age, number of needle passes, and platelet count were identified as reliable predictors of bleeding.

Keywords: ultrasound-guided, liver biopsy, bleeding, risk factor

\section{Introduction}

Despite the introduction of innovative noninvasive methods (eg, elastography), liver biopsy remains essential to the diagnosis, evaluation, and management of patients with liver disease. It is an irreplaceable means of identifying the cause of abnormal liver function, classifying/staging of fibrosis before and after treatment, and accurately diagnosing focal liver lesion. ${ }^{1-4}$ Percutaneous liver biopsy (PLB) is the preferred approach because it is less invasive and more cost-effective than other biopsy procedures. Ultrasound-guided PLB is safe and effective, having developed from "blind puncture" to "precision puncture"., 5 Real-time ultrasound guidance greatly reduces the risk of complications of obtaining a biopsy, such complications including damaging major blood vessels or bile ducts. $^{7-9}$

Ultrasound-guided PLB is widely performed in the field of clinical hepatology. ${ }^{10-14}$ However, this procedure is invasive, potential complications including pneumothorax, bleeding, and biliary fistula formation. Bleeding, the most important complication of liver biopsy, is sometimes life-threatening. ${ }^{4}$ This study was performed to analyze the risk factors for hemorrhagic complications after ultrasound-guided liver biopsies. 


\section{Patients and Methods}

Many factors have been reported to influence the incidence of bleeding, including coagulation status and number of needle passes. Most previous studies have been retrospective and many have not accounted for differences in potentially confounding factors between bleeding and nonbleeding groups. Therefore, in the present study, we analyzed selected baseline clinical and laboratory data to objectively evaluate possible risk factors for bleeding after liver biopsy. On the basis of a review of published reports on the incidence of post-procedure bleeding, we analyzed the effects of the following variables: age, sex, number of needle passes, focal lesion versus parenchymal, platelet count, prothrombin time (PT), and international normalized ratio (INR). ${ }^{8,15-19}$

From January 2018 to November 2020, 1092 patients underwent 1139 ultrasound-guided PLBs in our institution. After exclusion of those with missing data, 834 ultrasound-guided PLBs performed on 807 patients were examined. Relevant patient characteristics, indications for biopsy, laboratory findings, biopsy technique, hemorrhagic complications, and pathologic outcomes were collected from these patients' electronic medical records. The study was conducted in accordance with the principles stated in the Helsinki declaration and was approved by the ethics committee of our institution.

\section{Biopsy Procedure}

Prior to taking a biopsy, a comprehensive ultrasonic examination was routinely performed to exclude any contraindications, such as obvious expansion of intrahepatic bile ducts and significant arterialization of intrahepatic blood supply, and to plan the puncture site and path. Routine laboratory tests, including platelet count, INR, and hemoglobin ( $\mathrm{Hb})$ concentration, were performed within 1 week before the biopsy. An INR of $\leq 1.8$ and platelet count of $\geq 50,000 / \mathrm{mm}^{3}$ are used as a reference for safety in our institution. However, several biopsies were performed in patients with higher INRs and lower platelet counts (lowest platelet count: $31,000 / \mathrm{mm}^{3}$; highest INR: 2.03 ) because the potential benefits were considered to outweigh the risks. Fresh frozen plasma or platelet transfusions were administered to patients with low platelet counts (usually less than $40,000 / \mathrm{mm}^{3}$ ) or abnormalities in coagulation-related variables (INR: $>2$ ) to improve their coagulation function, after which the laboratory tests were repeated. Anti-platelet and anti-coagulant medications were discontinued at least 7 days before biopsy. Additionally, relevant laboratory tests were carefully monitored before biopsy in patients with a history of treatment with anti-platelet or anti-coagulant medications.

All biopsies were performed in a sterile room under aseptic conditions. They were performed via an intercostal or subxiphoid approach, the patient usually being placed in a supine or left supine position. Biopsies on adults and a few older cooperative children were performed under local lidocaine anesthesia, whereas most biopsies on children were performed under general anesthesia. The PLBs were performed by two radiologists, each with at least 6 years' experience in abdominal diagnostic ultrasound, one of whom had more than 3 years' experience in interventions. The biopsies were performed using an $18 \mathrm{G}$ Automated Cutting Needle (Bard Biopsy Systems, Tempe, AZ, USA) of 15- or 22-mm core length. The whole process of biopsy was guided by real-time ultrasound, enabling monitoring of the needle path and avoidance of large intrahepatic vessels and bile ducts. For biopsies of the liver parenchyma, the radiologist punctured 10 to $20 \mathrm{~mm}$ further after the tip of the needle had passed through the liver capsule, then pressed the trigger button to obtain a sample (Figure 1A). In our institution, one to three punctures are performed. For biopsies of focal liver lesions, the shortest distance and safest route were the prime considerations. Generally, the trigger button was pressed when the needle tip had reached or penetrated the target focal lesion (Figure 1B). During the process of puncture, the patients were asked to hold their breath, if possible, to minimize respiration-associated injuries. The specimens were fixed with $10 \%$ formalin and immediately sent to the pathology laboratory.

The biopsy point was compressed with a probe for about 5 minutes for both grayscale and color Doppler scanning to enable immediate detection of any postbiopsy bleeding. The observation time was extended if a "patent track" sign was still present at 5 minutes. ${ }^{20,21}$ If post-biopsy bleeding was detected, hemostatic measures were implemented to prevent further bleeding, sometimes necessitating radiological intervention or surgery. If no such abnormalities were detected, the biopsy point was compressed by the patient or one of their relatives for 30 minutes to minimize bleeding. A routine ultrasonic examination was performed within 24 hours after the biopsy to identify any bleeding complications. Hemoglobin and hematocrit were measured on the second post-biopsy day.

\section{Definitions of Bleeding Complications}

Bleeding complications were classified as major or minor. Major bleeding complications were defined as changes in 

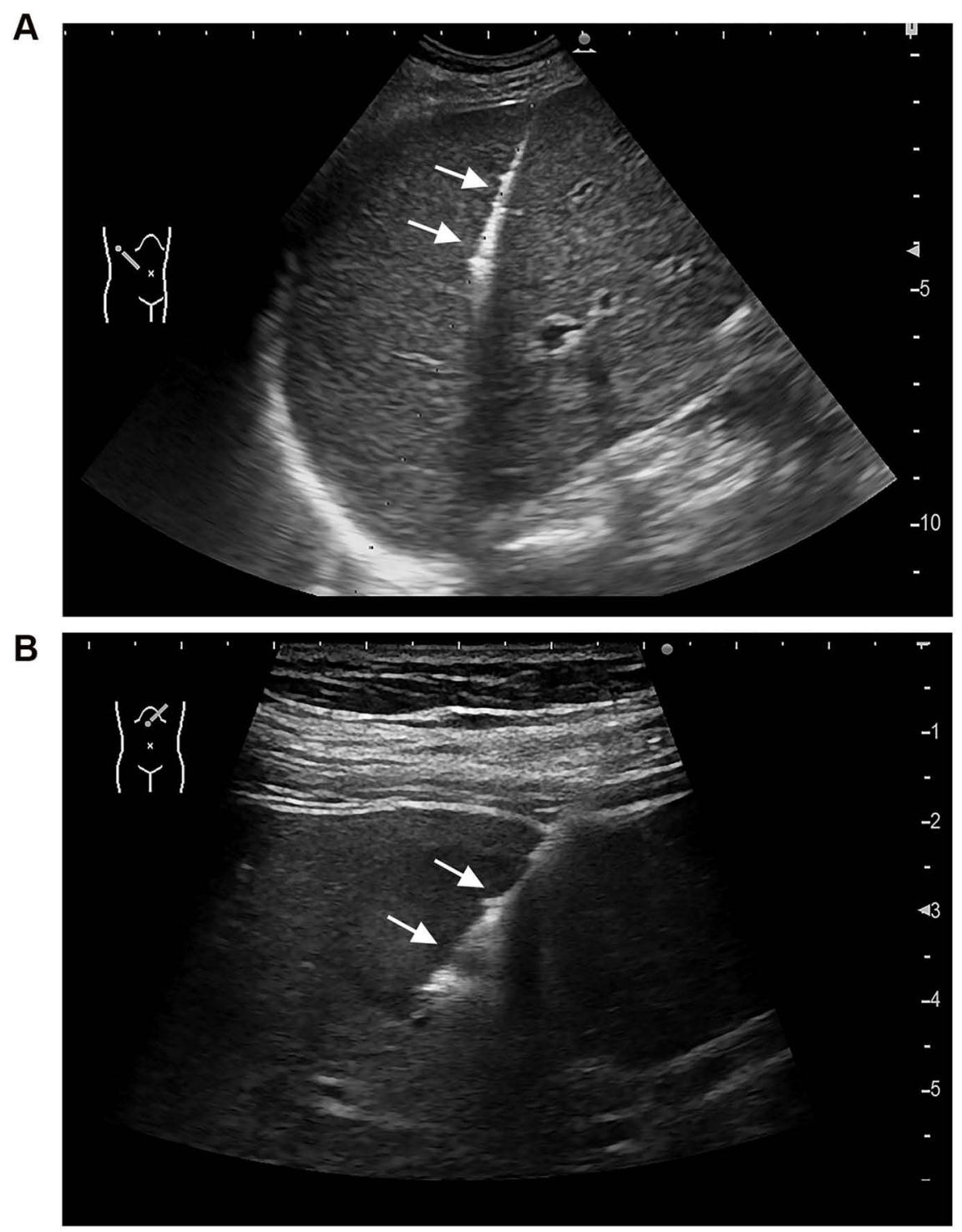

Figure I (A) Ultrasound image obtained during biopsy of the liver parenchyma of a 34-year-old man who had undergone liver transplantation 5 years previously (The needle track of biopsy is designated by the arrow). (B) Ultrasound image obtained during biopsy of a focal liver lesion in a 5-year-old boy (The needle track of biopsy is designated by the arrow).

vital signs with laboratory and/or radiological evidence of intraperitoneal bleeding requiring therapeutic interventions such as transfusion, radiological intervention, or surgery. Minor bleeding complications were defined as small hematomas or small amounts of free intra-abdominal blood (absent before procedure) identified on post-biopsy imaging (usually ultrasound) with no changes in vital signs or need for therapeutic intervention. ${ }^{19,22}$

\section{Statistical Analysis}

Statistical analyses were performed using SPSS version 22.0 software (IBM, Armonk, NY, USA) for Windows. Continuous variables were compared using the MannWhitney $U$-test or Student's $t$-test. Categorical variables were compared using the $\chi^{2}$ test. Variables showing statistical significance by univariate analysis were included in multivariate logistic regression. Normally distributed quantitative variables are expressed as mean \pm standard deviation, whereas those with a skewed distribution are expressed as median (interquartile range). A $p$ value of $<0.05$ (two-sided) was considered to denote statistical significance.

\section{Results}

\section{Patient Characteristics}

Our study groups were drawn from 834 procedures performed on 807 patients with a median age of 45 years (range: $0.40-85.00$ years). They comprised 440 (52.8\%) female and $394(47.2 \%)$ male patients. In total, 478 
(68.3\%) biopsies were for diagnostic purposes, the two most frequent indications being abnormal liver function tests $(\mathrm{n}=$ $252,30.2 \%)$ and evaluation of intrahepatic masses $(n=105$, $12.6 \%)$. Other relatively common indications included nonalcoholic fatty liver disease $(n=49,5.8 \%)$, primary biliary cirrhosis $(n=37,4.4 \%)$, portal hypertension $(n=14,1.7 \%)$, cirrhosis discovered on imaging ( $\mathrm{n}=14,1.7 \%)$, and autoimmune hepatitis $(\mathrm{n}=13,1.6 \%)$. Less common indications included evaluation of donor livers, cholestatic disorders, primary sclerosing cholangitis, pyrexia of unknown origin, alcoholic fatty liver disease, and Epstein-Barr virus infection (fewer than five cases each). Seventy biopsies were performed to monitor chronic liver disease associated with viral hepatitis $(\mathrm{n}=57,6.8 \%)$ or metabolic liver disease $(\mathrm{n}=$ $16,1.9 \%$ ). The remaining 264 biopsies were performed to evaluate transplanted livers; the indications being abnormal liver function tests $(\mathrm{n}=166,19.9 \%)$, protocol-mandated evaluation $(n=47,5.6 \%)$, acute graft dysfunction $(n=45$, $5.4 \%)$, and recurrent hepatitis $\mathrm{B}(\mathrm{n}=6,0.7 \%)$ (Table 1$)$. The median follow-up was 8.7 hours (interquartile range, 6.723.4 hours) after the biopsy. The data of all included patients were complete.

\section{Bleeding Complications}

The rate of bleeding complications was 5.40\% (Table 2). One patient had major bleeding $(0.12 \%)$ as evidenced by decreases in blood pressure and $\mathrm{Hb}$ concentration after transfusion and drug therapy; the bleeding was eventually stopped by hepatic artery embolization. A computed tomography scan showed evidence of hemoperitoneum (Figure 2A). The remaining $44(5.28 \%)$ patients had minor bleeding, which was identified by ultrasound evaluation within 24 hours after the biopsy. A small amount of free abdominal fluid was detected in 41 of these patients and intrahepatic hematomas in three (Figure 2B and C). There were no significant abnormalities in their vital signs or laboratory test findings such as hemoglobin concentration. None of these minor bleeding incidents required any specific intervention.

\section{Baseline Data}

The bleeding group comprised 45 patients and the nonbleeding group the remaining 789. Table 3 shows clinical variables in the observation $(n=45)$ and control group ( $n$ = 789). There were no significant differences in alanine aminotransferase, alanine aminotransferase/aspartate aminotransferase, total bilirubin, or hepatitis B surface antigen positivity between these groups.
Table I Indications for Liver Biopsy

\begin{tabular}{|l|l|}
\hline Indications & Biopsies \\
\hline Diagnostic & $252(30.2 \%)$ \\
\hline Abnormal Liver Tests & $105(12.6 \%)$ \\
Evaluation of intrahepatic masses & $49(5.8 \%)$ \\
NAFLD & $37(4.4 \%)$ \\
Primary biliary cirrhosis & $14(1.7 \%)$ \\
Portal hypertension & $14(1.7 \%)$ \\
Cirrhosis by imaging & $13(1.6 \%)$ \\
Autoimmune hepatitis & $13(1.6 \%)$ \\
Others & \multicolumn{2}{|l}{} \\
\hline Monitoring chronic diseases & $57(6.8 \%)$ \\
\hline Viral hepatitis & $16(1.9 \%)$ \\
Metabolic liver diseases & $166(19.9 \%)$ \\
\hline Evaluating transplanted liver & $47(5.6 \%)$ \\
\hline Abnormal liver function & $45(5.4 \%)$ \\
Periodic evaluation & $6(0.7 \%)$ \\
Acute graft dysfunction &
\end{tabular}

Abbreviations: HBV, hepatitis B virus; NAFLD, non-alcoholic fatty liver disease.

Table 2 Bleeding Complications

\begin{tabular}{|l|l|}
\hline Bleeding Complications & Number(Proportion) \\
\hline Major bleeding requiring intervention & $\mathrm{I}(0.12 \%)$ \\
Perihepatic/Perisplenic effusion & $24(2.88 \%)$ \\
Interintestinal effusion & $13(1.56 \%)$ \\
$\begin{array}{l}\text { Perihepatic/perisplenic effusion and } \\
\text { interintestinal effusion }\end{array}$ & $4(0.48 \%)$ \\
Intrahepatic hematomas & $3(0.36)$ \\
\hline
\end{tabular}

\section{Univariate Analysis of Risk Factors for Bleeding}

Factors that could potentially affect post-procedure bleeding were subjected to univariate analysis. As shown in Table 3, we found that children (aged under 18 years) were more prone to bleeding than adults. The incidence of post-procedure bleeding did not differ significantly between female and male patients. There was no significant difference in bleeding risk between biopsies of liver focal lesions versus of liver parenchyma ( $35.71 \%$ vs $18.71 \%$; $p=0.88$ ). Two or three needle passes were associated with a higher risk of post-procedure bleeding than was one needle pass $(p=0.009)$. Age, number of needle passes, platelet count, PT, and INR were all significantly associated with postprocedure bleeding (all $p<0.05$ ). 


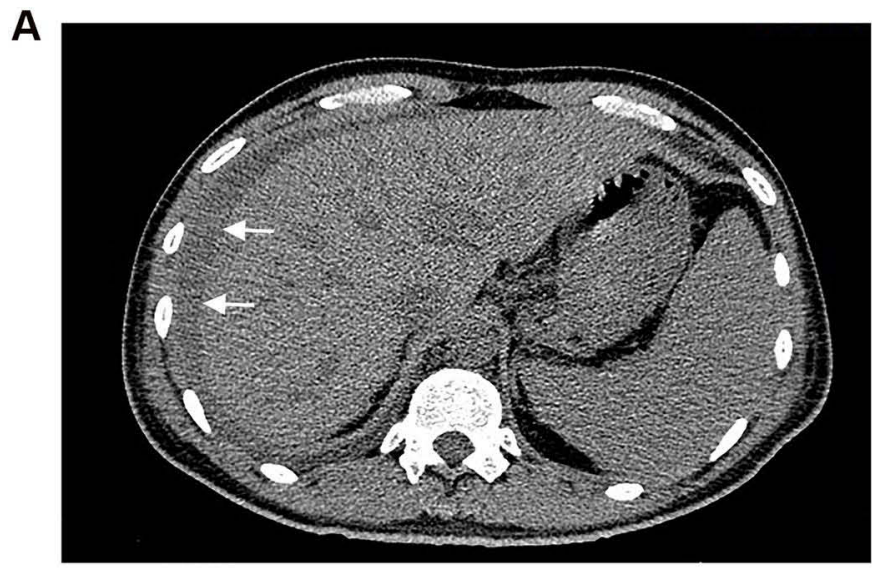

B
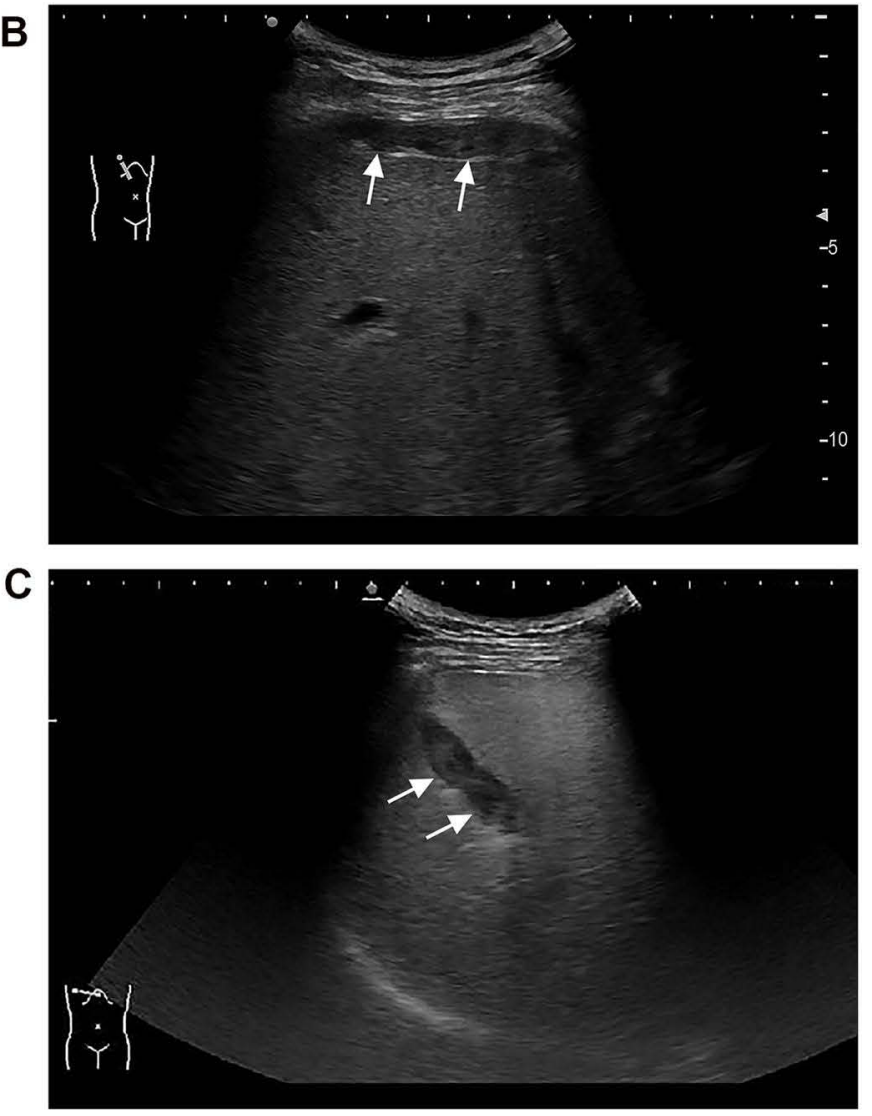

Figure 2 (A) Computed tomography image obtained 6 hours after PBL showing a hemoperitoneum in a 40-year-old man (The perihepatic hemorrhage is designated by the arrow). (B) Ultrasound image obtained 18 hours after PBL showing perihepatic free abdominal fluid in a $6 \mathrm{I}$-year-old woman (The perihepatic free abdominal fluid is designated by the arrow). (C) Ultrasound image obtained 12 hours after PBL showing an intrahepatic hematoma in a 56-year-old man (The intrahepatic hematoma is designated by the arrow).

\section{Multivariate Analysis of Risk Factors for Bleeding}

The factors found to differ significantly by univariate analysis were further analyzed by multivariate analysis, which identified that age under 18 years $(\mathrm{P}<0.001 ; \mathrm{OR}=0.277)$ two or three needle passes $(\mathrm{P}=0.023$; OR $=2.193)$, and a low platelet count $(\mathrm{P}=0.001 ; \mathrm{OR}=0.993)$ were predictors of post-procedure bleeding (Table 4). The other assessed factors were not predictors of post-procedure bleeding.

\section{Discussion}

In this study, $5.40 \%$ of patients who underwent liver biopsy developed a bleeding complication, which is slightly higher than reported bleeding rates of $0.32 \%$ to 
Table 3 Comparisons of Clinical Variables Between Groups

\begin{tabular}{|c|c|c|c|}
\hline & Bleeding Group & Non-Bleeding Group & $\mathbf{P}$ \\
\hline Age & & & $<0.001^{\mathrm{a}}$ \\
\hline Children & 22 & 181 & \\
\hline Adults & 23 & 608 & \\
\hline Sex & & & $0.146^{\mathrm{a}}$ \\
\hline Male & 26 & 368 & \\
\hline Female & 19 & 421 & \\
\hline Passes of biopsy & & & $0.009^{\mathrm{a}}$ \\
\hline I & 29 & 635 & \\
\hline$\geq 2$ & 16 & 154 & \\
\hline Biopsy target & & & $0.877^{\mathrm{a}}$ \\
\hline Focal lesion & 6 & 99 & \\
\hline Liver parenchyma & 39 & 690 & \\
\hline $\mathrm{HbsAg}$ & & & $0.421^{\mathrm{a}}$ \\
\hline Positivity & 2 & 72 & \\
\hline Negativity & 43 & 717 & \\
\hline ALT & $62.00(18.50,163.00)$ & $39.00(21.00,92.00)$ & $0.236^{\mathrm{b}}$ \\
\hline ALT/AST & I.07(0.79, I.88) & $1.00(0.73,1.45)$ & $0.119^{\mathrm{b}}$ \\
\hline T-BIL & $17.02(9.33,49.47)$ & $14.93(10.11,24.59)$ & $0.228^{\mathrm{b}}$ \\
\hline Platelet Count & $148.00(103.00,214.50)$ & $204.00(145.00,259.00)$ & $0.002^{\mathrm{b}}$ \\
\hline PT & $12.60(11.60,13.55)$ & $11.70(11.20,12.50)$ & $<0.001^{b}$ \\
\hline INR & $1.11(1.04,1.25)$ & $1.04(0.97,1.13)$ & $<0.001^{\mathrm{b}}$ \\
\hline
\end{tabular}

Notes: ${ }^{\mathrm{a}} \chi^{2}$ test; ${ }^{\mathrm{b}}$ Mann-Whitney $U$-test.

Abbreviations: ALT, alanine aminotransferase; AST, aspartate aminotransferase; T-BIL, total bilirubin; HbsAg, hepatitis B surface antigen; INR, international normalized ratio; PT, prothrombin time.

Table 4 Results of Multivariate Analysis of Possible Predictors of Bleeding Complication

\begin{tabular}{|l|l|l|l|}
\hline Factors & P & OR & 95\% Cl \\
\hline Age & $<0.001$ & 0.269 & $0.134-0.541$ \\
Number of needle passes & 0.025 & 2.174 & $1.104-4.282$ \\
Platelet Count & 0.001 & 0.993 & $0.988-0.997$ \\
PT & 0.247 & 1.541 & $0.740-3.208$ \\
INR & 0.850 & 0.510 & $0.000-562.757$ \\
\hline
\end{tabular}

Abbreviations: $\mathrm{Cl}$, confidence interval; OR, odds ratio.

1.9\%. ${ }^{16-18,23,24}$ This discrepancy may be attributable to differences in the definitions of bleeding.

Additionally, post-biopsy ultrasound examination was not routinely performed in some of those studies, possibly resulting in underestimation of the incidence of postprocedure bleeding. Furthermore, efficient control of bleeding can be achieved by embolization of the biopsy track when using a coaxial technique. However, in our institution biopsies are performed using a non-coaxial technique, despite reports that a coaxial technique is preferable when obtaining biopsies for patients at high risk of bleeding. This factor may have enhanced the rate of bleeding in this study.

Most previous studies of post-procedure bleeding have been retrospective cohort studies, and some did not take into account confounding factors such as liver function, which may affect the risk of this complication. In this study, we found no significant differences in clinical variables, such as alanine aminotransferase and total bilirubin, between the two groups, which suggests that potentially confounding biases may have been minimal.

In our cohort, the rate of bleeding complications after biopsy was $10.83 \%$ for children, which is comparable with previously reported rates (4.6-18\%). In this study, children had a higher risk of bleeding than did adults (3.78\%). Bilreiro et al $^{19}$ also found that younger children showed 
a higher rate of bleeding complications than did older children. In line with this, Azzam et al reported a higher risk of complications of PLB in infants aged less than three months than in older children. There is no clear explanation for younger children being at greater risk of post-procedure bleeding. One possible reason is that children mostly undergo the procedure under general anesthesia and are therefore unable to hold their breath during puncture. Another possible explanation is that the blood vessels in children's livers are narrow and therefore difficult to detect by ultrasonography. Thus, these small vessels may be damaged during puncture, causing bleeding. For these reasons, the biopsy index should be strictly monitored before the procedure in younger children and the risk of bleeding minimized by compressing the puncture point for longer and keeping the patient in bed after the procedure.

With respect to biopsies of focal lesions, Westheim et al analyzed 275 biopsies in a pediatric cohort and found significant differences in bleeding rates between focal lesions and parenchyma. They reported that a focal lesion is an independent risk factor for post-biopsy bleeding. ${ }^{25}$ We therefore investigated this possibility in the present study but found no significant difference in the rates of post-procedure bleeding between biopsies of focal lesions and parenchyma. This discrepancy may be attributable to the greater number of passes for focal lesions and the smaller sample size in the study by Westheim et al's study. A 10-year analysis of 1961 patients by Mueller et al revealed no significant differences in bleeding complication rates between different puncture targets (focal lesions and parenchyma). ${ }^{26}$ Additionally, $\mathrm{Yu}$ et al studied the rate of bleeding complications after biopsy of hepatocellular carcinomas of varying size. They categorized tumor size into four groups and found no statistically significant differences in bleeding rates among those groups. ${ }^{27}$

In the present study, the rate of biopsy-related bleeding complications after two or three needle passes versus after only one needle pass differed significantly. Similarly, in the study Bilreiro et al conducted on liver biopsies in children, the incidence of post-procedure bleeding increased significantly in parallel with the number of needle passes. ${ }^{19}$ Chi et al analyzed 1806 liver biopsies and reported that three or more needle passes were associated with an increased risk of complications, whereas the risk of complications did not differ between one and two needle passes. ${ }^{18}$ However, they assessed the risk of all complications, not just bleeding. Thus, the number of needle passes should be minimized in patients at high risk of bleeding to reduce the risk of this complication.

Associations between platelet count, coagulationrelated variables, and post-procedure bleeding are currently controversial. Mueller et al reported that normal or mildly reduced platelet counts and coagulation-related variables do not correlate with incidence of bleeding complications. ${ }^{26}$ However, Terjung et al reported that prebiopsy platelet counts are a significant independent risk factor for bleeding complications. ${ }^{28}$ In the present study, the platelet count, PT, and INR were all significantly correlated with bleeding after puncture according to univariate analysis. However, according to multivariate analysis, only the platelet count was significantly associated with bleeding risk. Seeff et al analyzed data on liver biopsies in patients with advanced chronic liver disease and found a clear relationship between the platelet count and risk of bleeding. They found that the incidence of bleeding increased with decreasing platelet count, being particularly high when the platelet count was less than $60,000 / \mathrm{mm} 3 .{ }^{16}$ Several studies have reported that, in patients with cirrhosis, a prolonged PT is not strongly associated with an increased risk of bleeding complications..$^{29,30}$ The INR, a standardized form of PT, can only play a limited role as a predictor of postprocedure bleeding because it is not applicable in patients with abnormal procoagulant or anticoagulant systems. ${ }^{31,32}$ However, the INR can be taken into consideration in patients without liver cirrhosis. Findings of our own and previous studies suggest that the INR should be no more than 1.8 and that platelet count, PT, and INR should be assessed before liver biopsy. The pros and cons for biopsy should be weighed up in patients with low platelet counts and abnormal coagulation-related variables. However, it is worth noting that the requirements for coagulation function should be less stringent in patients with cirrhosis. If biopsy is considered essential in patients with low platelet counts andlor coagulation-related variables, measures to prevent bleeding, such as radiofrequency ablation of the needle tract, ${ }^{33,34}$ should be planned. Transjugular liver biopsy is another alternative, enabling performing multiple passes without increasing the risk of bleeding. ${ }^{35,36}$

This study had several limitations. First, it was a single-center, retrospective study; thus, there may have been confounding and selection biases and discrepancies between different research centers. Additionally, bleeding events may be underestimated in the case of bleeding that 
occurs after routine post-biopsy ultrasonic examination. However, previous studies have shown that the great majority of post-procedural bleeding complications occur within the first 24 hours, ${ }^{37}$ which suggests that only a small minority of bleeding complications would be missed. An additional significant limitation is that we only studied PLB by core tissue biopsy (18G) in patients with various categories of liver disease. Thus, the findings may be different for other gauges of puncture needles.

In conclusion, in this study we further demonstrated that ultrasound-guided liver biopsy is an efficacious procedure with a low incidence of complications. We found age, number of needle passes, and platelet count to be reliable predictors of bleeding. INR and PT were associated with an increase in the incidence of bleeding, however they had no predictive value. Additionally, factors such as sex and focal liver lesions were not associated with higher rates of bleeding complications.

\section{Ethics Statement}

This study was approved by the Ethics Committee of Beijing Friendship Hospital affiliated to Capital Medical University (Approved number:2021-P2-032-01). Due to the retrospective nature of the study, the informed consent application was waived. All patient data were anonymously recorded and securely protected to ensure patient confidentiality.

Besides, the use of organs from executed prisoners as transplant donors had been completely prohibited, and voluntary organ donation by deceased citizens and living organ donation by patient's close relatives are the only two channels for liver transplantation. All the organs were donated voluntarily with written informed consent, and the donation was conducted in accordance with the Declaration of Istanbul.

\section{Acknowledgment}

We thank Dr Trish Reynolds, MBBS, FRACP, from Liwen Bianji, Edanz Group China (http://www.liwenbianji.cn/), for editing the English text of a draft of this manuscript.

\section{Author Contributions}

All authors contributed to data analysis, drafting or revising the article, gave final approval of the version to be published, agreed to the submitted journal, and agree to be accountable for all aspects of the work.

\section{Funding}

This research was supported by the Capital's Funds for Health Improvement and Research of China (20204-20211).

\section{Disclosure}

The authors report no conflicts of interest for this work.

\section{References}

1. Bedossa P. Liver biopsy. Gastroenterol Clin Biol. 2008;32(6 Suppl 1):4-7. doi:10.1016/S0399-8320(08)73989-7

2. Bravo AA, Sheth SG, Chopra S. Liver biopsy. $N$ Engl J Med. 2001;344(7):495-500. doi:10.1056/NEJM200102153440706

3. Khalifa A, Rockey DC. The utility of liver biopsy in 2020. Curr Opin Gastroenterol. 2020;36(3):184-191. doi:10.1097/MOG.000000 0000000621

4. Rockey DC, Caldwell SH, Goodman ZD, Nelson RC, Smith AD; American Association for the Study of Liver D. Liver biopsy. Hepatology. 2009;49(3):1017-1044. doi:10.1002/hep.22742

5. Copel L, Sosna J, Kruskal JB, Kane RA. Ultrasound-guided percutaneous liver biopsy: indications, risks, and technique. Surg Technol Int. 2003;11:154-160.

6. Nobili V, Comparcola D, Sartorelli MR, et al. Blind and ultrasound-guided percutaneous liver biopsy in children. Pediatr Radiol. 2003;33(11):772-775. doi:10.1007/s00247-003-1044-0

7. Rustagi T, Newton E, Kar P. Percutaneous liver biopsy. Trop Gastroenterol. 2010;31(3):199-212.

8. Tian G, Kong D, Jiang T, Li L. Complications after percutaneous ultrasound-guided liver biopsy: a systematic review and meta-analysis of a population of more than 12,000 patients from 51 cohort studies. J Ultrasound Med. 2020;39(7):1355-1365. doi: $10.1002 /$ jum. 15229

9. Al Knawy B, Shiffman M. Percutaneous liver biopsy in clinical practice. Liver Int. 2007;27(9):1166-1173. doi:10.1111/j.14783231.2007.01592.x

10. Sornsakrin M, Helmke K, Briem-Richter A, Ganschow R. Value of ultrasound-guided percutaneous liver biopsy in children following liver transplantation. J Pediatr Gastroenterol Nutr. 2010;51 (5):635-637. doi:10.1097/MPG.0b013e3181e7e832

11. Kim JS, Won HJ, Lee SJ, Kim SY, Shin YM, Kim PN. Utility and safety of repeated ultrasound-guided core needle biopsy of focal liver masses. J Ultrasound Med. 2018;37(2):447-452. doi:10.1002/ jum. 14358

12. Rothuizen J, Twedt DC. Liver biopsy techniques. Vet Clin North Am Small Anim Pract. 2009;39(3):469-480. doi:10.1016/j.cvsm.200 9.02.006

13. Padia SA, Baker ME, Schaeffer CJ, et al. Safety and efficacy of sonographic-guided random real-time core needle biopsy of the liver. J Clin Ultrasound. 2009;37(3):138-143. doi:10.1002/jcu.20553

14. Sebagh M, Rifai K, Féray C, et al. All liver recipients benefit from the protocol 10-year liver biopsies. Hepatology. 2010;37 (6):1293-1301.

15. Poorten D, Kwok A, Lam T, Ridley L, Lee AU. Twenty-year audit of percutaneous liver biopsy in a major Australian teaching hospital. Intern Med J. 2010;36(11):692-699. doi:10.1111/j.1445-5994.20 06.01216.x

16. Seeff LB, Everson GT, Morgan TR, Curto TM, Dienstag JL. Complication rate of percutaneous liver biopsies among persons with advanced chronic liver disease in the HALT-C trial. Clin Gastroenterol Hepatol. 2010;8(10):877-883. doi:10.1016/j.cgh.201 0.03 .025 
17. Takyar V, Etzion O, Heller T, et al. Complications of percutaneous liver biopsy with Klatskin needles: a 36-year single-centre experience. Aliment Pharmacol Ther. 2017;45(5):744-753. doi:10.1111/apt.13939

18. Chi H, Hansen BE, Tang WY, et al. Multiple biopsy passes and the risk of complications of percutaneous liver biopsy. Eur J Gastroenterol Hepatol. 2017;29(1):36-41. doi:10.1097/ MEG.0000000000000731

19. Bilreiro C, Noruegas MJ, Goncalves I, Moreira A. Ultrasound-guided liver biopsies in children: a single-center experience and risk factors for minor bleeding. J Pediatr Gastroenterol Nutr. 2017;65 (2):137-140. doi:10.1097/MPG.0000000000001601

20. Kim KW, Kim MJ, Kim HC, Park SH, Kim TK. Value of "patent track" sign on Doppler sonography after percutaneous liver biopsy in detection of postbiopsy bleeding: a prospective study in 352 patients. Am J Roentgenol. 2007;189(1):109-116. doi:10.2214/AJR.07.2071

21. Midia M, Odedra D, Shuster A, et al. Predictors of bleeding complications following percutaneous image-guided liver biopsy: a scoping review. Diagn Interv Radiol. 2019;25(1):71-80. doi:10.5152/ dir.2018.17525

22. Westheim BH, Aagenaes I, Ostensen AB, Sanengen T, Almaas R. Effect of operator experience and frequency of procedure performance on complication rate after ultrasound-guided percutaneous liver biopsies. J Pediatr Gastroenterol Nutr. 2013;57(5):638-643. doi:10.1097/MPG.0b013e3182a0c7a5

23. Myers RP, Fong A, Shaheen A. Utilization rates, complications and costs of percutaneous liver biopsy: a population-based study including 4275 biopsies. Liver Int. 2010;28(5):705-712. doi:10.1111/ j.1478-3231.2008.01691.x

24. Huang JF, Hsieh MY, Dai CY, et al. The incidence and risks of liver biopsy in non-cirrhotic patients: an evaluation of 3806 biopsies. Gut. 2007;56(5):736-737. doi:10.1136/gut.2006.115410

25. Westheim BH, Ostensen AB, Aagenaes I, Sanengen T, Almaas R. Evaluation of risk factors for bleeding after liver biopsy in children. $J$ Pediatr Gastroenterol Nutr. 2012;55(1):82-87. doi:10.1097/ MPG.0b013e318249c12a

26. Mueller M, Kratzer W, Oeztuerk S, et al. Percutaneous ultrasonographically guided liver punctures: an analysis of 1961 patients over a period of ten years. BMC Gastroenterol. 2012;12:173. doi:10.1186/ 1471-230X-12-173
27. Yu SC, Metreweli C, Lau WY, et al. Safety of percutaneous biopsy of hepatocellular carcinoma with an 18 gauge automated needle. Clin Radiol. 1997;52(12):907. doi:10.1016/S0009-9260(97)80222-X

28. Terjung B, Lemnitzer I, Dumoulin FL, et al. Bleeding complications after percutaneous liver biopsy. An analysis of risk factors. Digestion. 2003;67(3):138-145. doi:10.1159/000071293

29. Segal JB, Dzik WH. Paucity of studies to support that abnormal coagulation test results predict bleeding in the setting of invasive procedures: an evidence-based review. Transfusion. 2010;45 (9):1413-1425. doi:10.1111/j.1537-2995.2005.00546.x

30. Tripodi A, Salerno F, Chantarangkul V, et al. Evidence of normal thrombin generation in cirrhosis despite abnormal conventional coagulation tests. Hepatology. 2005;41(3):553-558. doi:10.1002/ hep. 20569

31. Trotter JF, Olson J, Lefkowitz J, Smith AD, Arjal R, Kenison J. Changes in international normalized ratio (INR) and model for endstage liver disease (MELD) based on selection of clinical laboratory. Am J Transplant. 2010;7(6):1624-1628. doi:10.1111/j.16006143.2007.01822.x

32. Lisman T, Van Leeuwen $\mathrm{Y}$, Adelmeijer $\mathrm{J}$, et al. Interlaboratory variability in assessment of the model of end-stage liver disease score. Liver Int. 2010;28(10):1344-1351. doi:10.1111/j.14783231.2008.01783.x

33. Song KD, Rhim H, Lee MW, Kang TW, Lim S. A radiofrequency device for tract ablation after liver biopsy: a single-institution human feasibility study. Br J Radiol. 2018;91(1085):20170585. doi:10.1259/ bjr.20170585

34. Sag AA, Brody LA, Maybody M, et al. Acute and delayed bleeding requiring embolization after image-guided liver biopsy in patients with cancer. Clin Imaging. 2016;40(3):535-540. doi:10.1016/j. clinimag.2015.11.004

35. Pathak K, Gopinath M, Salgotra KR. Transjugular liver biopsy. Med $J$ Armed Forces India. 2013;69(4):384-387. doi:10.1016/j. mjafi.2013.04.003

36. Ble M, Procopet B, Miquel R, Hernandez-Gea V, Garcia-Pagan JC. Transjugular liver biopsy. Clin Liver Dis. 2014;18(4):767-778. doi:10.1016/j.cld.2014.07.001

37. Dotan Y, Carlebach M, Zuckerman E, Maruf M, Schiff E. Delayed bleeding after percutaneous liver biopsy. Eur J Case Rep Intern Med. 2016;3(2):000359.
International Journal of General Medicine

\section{Publish your work in this journal}

The International Journal of General Medicine is an international, peer-reviewed open-access journal that focuses on general and internal medicine, pathogenesis, epidemiology, diagnosis, monitoring and treatment protocols. The journal is characterized by the rapid reporting of reviews, original research and clinical studies across all disease areas. The manuscript management system is completely online and includes a very quick and fair peer-review system, which is all easy to use. Visit http://www.dovepress.com/ testimonials.php to read real quotes from published authors. 